\title{
New upper bounds for the forgotten index among bicyclic graphs
}

\author{
Jonnathan Rodriguez ${ }^{1}$, Akbar Jahanbani ${ }^{2}$, Seyed Mahmoud Sheikholeslami ${ }^{3}$, Reza Rasi ${ }^{3}$, \\ and L Shahbazi ${ }^{3}$ \\ ${ }^{1}$ Universidad de Antofagasta \\ ${ }^{2}$ Shahrood University of Technology \\ ${ }^{3}$ Azarbaijan Shahid Madani University
}

November 25, 2020

\begin{abstract}
The forgotten topological index of a graph $\$ \mathrm{G} \$$, denoted by $\$ \mathrm{~F}(\mathrm{G}) \$$, is defined as the sum of weights $\$ \mathrm{~d}(\mathrm{u})^{\wedge}\{2\}+\mathrm{d}(\mathrm{v})^{\wedge}\{2\} \$$ over all edges $\$ \mathrm{uv} \$$ of $\$ \mathrm{G} \$$, where $\$ \mathrm{~d}(\mathrm{u}) \$$ denotes the degree of a vertex $\$ \mathrm{u} \$$. In this paper, we give sharp upper bounds of the F-index (forgotten topological index) over bicyclic graphs, in terms of the order and maximum degree.
\end{abstract}

\section{Hosted file}

New upper bounds for the forgotten index among bicycliv graphs.pdf available at https: //authorea.com/users/378620/articles/495076-new-upper-bounds-for-the-forgotten-indexamong-bicyclic-graphs 